\title{
RETRIVAL OF BIO-PHYSICAL PARAMETERS IN SUNFLOWER CROP (Helianthus annuus) USING FIELD BASED HYPERSPECTRAL REMOTE SENSING
}

\author{
Prabhat Kanti Routh ${ }^{1,{ }^{*}}$, Narayan Chandra Sarkar ${ }^{2}$, Prabir Kumar Das ${ }^{1}$, Dipak Debnath ${ }^{2}$, S. Bandyopadhyay ${ }^{1}$, Uday Raj $^{3}$ \\ ${ }^{1}$ Regional Remote Sensing Centre- East, National Remote Sensing Centre, Kolkata- prabhatkanti.routh@gmail.com \\ (prabirkumar_d, bandyo_s)@nrsc.gov.in \\ ${ }^{2}$ Dept. of Agronomy, Visva Bharati University, Birbhum, India- nciari@gmail.com \\ ${ }^{3}$ Regional Centres, NRSC,ISRO, Telengana, India - uday_raj@nrsc.gov.in
}

Commission III, WG III/10

KEY WORDS: sunflower, hyperspectral remote sensing, bio-physical parameters, leaf area index, chlorophyll content index, fluorescence

\begin{abstract}
:
Information on several crop bio-physical parameters is important as inputs for crop growth modelling, leaf stress analysis, crop health study and productivity point of view. Conventionally, biophysical parameters are measured in laboratory methods which are time consuming, laborious and destructive in nature. With the advent of remote sensing technology, the limitations of conventional methods can be overcome. Moreover, due to its narrow absorption bands at different wavelength, use of hyperspectral remote sensing becomes very useful in retrieving several bio-physical parameters. In the present study, field as well as laboratory based spectro-radiometer observations were carried out at Agronomy Department of VisvaBharati University, West Bengal, on Sunflower crop at its peak vegetation stage towards retrieving different bio-physical parameters, specifically leaf area index (LAI), chlorophyll content index (CCI), fluorescence etc. Different foliar boron (no boron, $0.15 \%$ and $0.20 \%$ ) and irrigation (4-6 irrigations) treatments, i.e. total nine treatments with three replications, were applied on sunflower crop during different phenological stages to achieve maximum ranges of the bio-physical parameters. The LAI, CCI and fluorescence parameters were collected using canopy analyzer, chlorophyll content meter and portable gas exchange system, respectively. In each of the treatments, total four hyperspectral measurements were collected, which were further corrected for noise and smoothened using Savitzky-Golay filtering. Total thirtyfour narrow band indices were computed based on the hyperspectral data, and the regression analysis was carried out among the indices and bio-physical parameters. The regression parameters were further deployed on the hyperspectral indices to retrieve the bio-physical parameters. The Gitelson\& Merzylak-1 (GM-1) and Carter Indices-1 (CI-1) were found to the best indices for retrieving the LAI and CCI, respectively with correlation correlation (r) values of 0.87 and 0.80 . On the other hand, Normalized Phaenophytinization Index (NPQI) and GM-1 were found to best for retrieving the Fv/Fm (dark) and Fv'/Fm' (light) with correlation (r) values of 0.92 and 0.76 , respectively. Hence, the hyperspectral remote sensing be successfully utilized for retrieving several biophysical parameters both at field (canopy level) and laboratory (leaf level) conditions.
\end{abstract}

\section{INTRODUCTION}

India is the fourth largest edible oil economy in the world after the USA, Brazil and China. It occupies a distinct position not only in terms of area under oilseeds crops, but also in terms of diversity in cultivated oilseeds (http://agricrop.nic.in). The country has 19 per cent of world area under oilseeds, which accounts for only 9 per cent of world's production to meet the need of 16 per cent of the population. Nine oilseed crops vizgroundnut, rapeseed-mustard, soybean, sesame, linseed, castor, safflower, sunflower and niger grown in India comprise of the second largest commodity after cereal, sharing 14 per cent of the gross cropped area, accounting for 5 per cent of the gross national product and 10 per cent of the value of the agricultural products ( $w w w$.indialawoffices.com/ilo pdf/indu stry reports/edibleoilsindustry.pdf). According to twelfth five year plan it is necessary to produce 40 million tons of oilseeds to maintain parity when examined in the light of fact that the current level of production in these crops is only around 28 million tonnes (http://gcirc.org/fileadmin/documents/Bulletins /B26/B265RKGupta.pdf). This wide gap between supply and demand has created due to increasing population improvement in the standard of living and stagnation in production of both groups of crops. Indian agriculture needs to be more knowledge intensive in order to keep pace with growing population pressure and diminishing land and energy resources. Government of India is giving special importance to enhance their production of oil seed crops mainly to avoid heavy import bill every year. In grey areas of the country, production of oilseeds can be increased by adaption of location-specific cropping systems in which sunflower can be grown in rabi season and can be the most important crops of dryland areas with limited water availability under marginal and sub-marginal lands of India. It covers an area around 487.19 thousand hectares and 296.3 thousand MT of total production with $608 \mathrm{~kg} / \mathrm{ha}$ average productivity in the year of 2015-16(www.sopa.org/india-oilseeds-area-production-andproductivity). The existing yield is very low in India, mainly because of the sub-optimal soil fertility. There is ample scope of increasing production by use of agronomic as well as proper fertility management. An advance detection of crop stress is very important to manage the production inputs like water, fertilizer, pesticide for the reduction the risk associate with production of crop. A suitable combination of major and micronutrients is by and large the most important single factor that affects the yield and quality of safflower

*Corresponding author 
(www.careratings.com/upload/NewsFiles/SplAnalysis/Outloo $\underline{k}$ of Indian Edible Oil Industry.pdf). Sunflower (Helianthus annuus) is one of the most sensitive crops to low boron supply and applications of fertilizers containing boron increases sunflower production. The boron requirement of sunflower is much higher during reproductive growth compare to vegetative growth, and the malfunctioning of crops due to boron is generally observed during this phenophase. In addition to the boron content of soil, the availability of soil moisture also affects the boron uptake by plants. The health and growth of the crop can be evaluated in terms of different biophysical parameters, LAI, CCI, fluorescence. By adopting remote sensing technology, non-destructive analysis of the plant samples can be carried out toward retrieving the biophysical parameters (http://www.tandfonline.com/loi/tres20). Moreover, hyper spectral remote sensing provides information at very narrow spectral interval which may provide useful information for improved discrimination of plant growth status under different irrigation and boron treatments (http://www.tandfonline.com/loi/tres20).

Thus, the objectives of this study were to (1) study the effect of irrigation on crop growth and yield (2) study the effect of different level of foliar spray of boron on crop growth (3) explore the potential of hyperspectral remote sensing to capture the impact of boron and irrigation on Sunflower growth and productivity.

\section{MATERIALS AND METHODS}

\subsection{Study Area}

The experiment was carried out on sunflower crop (Helianthus annuus) in the month of May 2018 at Agronomy department of Visva Bharati University, Birbhum district, West Bengal (Lat $23.6776^{0} \mathrm{~N}$, Long $\left.87.6852^{\circ} \mathrm{E}\right)$. The experimental site is representative to determine the optimal doses of irrigation and foliar boron application. The climate is tropical in Bolpur. This climate is considered to be Average Weather according Koppen Geiger climate classification. The average annual temperature is $26.3^{0} \mathrm{C}$ with average precipitation of $1287 \mathrm{~mm}$. The maximum amount of precipitation occurs in July, with an average of $295 \mathrm{~mm}$. The experimental fields were composed of 27 plots based on the different levels of irrigation $(6,5,4$ named as M1, M2, M3, respectively) and foliar boron applications $(0 \%, 0.15 \%, 0.20 \%$ named as S1, S2, S3 respectively). There are 3 replicas of above combination of treatments.

\subsection{Data collection}

Biophysical parameters, viz. Leaf Area Index (LAI) and chlorophyll content index (CCI), and physiological parameters viz. Fluorescence, photosynthesis data along with spectral reflectance observations, were collected during crop peak growing period. LAI was measured using an LAI2200C instrument (Plant Canopy Analyzer). In each plot, the acquisitions were made along a transect composed of one above and three below-canopy readings, and data were postprocessed to discard the last ring readings (Stroppiana et al. 2006). Non-destructive measurements of chlorophyll concentration were carried out by relative measurement of transmittance between $931 \mathrm{~nm}$ and $653 \mathrm{~nm}$ by means of two light emitting diode in a Chlorophyll meter (MC-100, Apogee Instrument). For each plot, CCI readings were measured on an individual sunflower plant replicated five times, i.e. four at corners and one at the centre of the replica. To avoid the edge effect, a $50 \mathrm{~cm}$ buffer had been taken from all corners of plot. For each plant, CCI readings were collected for the fully expanded first five leaves starting from the top. For physiological parameters, photosynthesis processes are measured like net $\mathrm{CO}_{2}$ assimilation (A), transpiration (E), stomata conductance (gsw), intercellular $\mathrm{CO}_{2}$ concentration $\left(\mathrm{C}_{\mathrm{i}}\right)$, electron transport rate (ETR), non-photochemical quenching (NPQ), quantum yield of photo system II (Ф PSII) and several other processes etc by using portable photosynthesis system LI-6800XTF. An expanded leaf was covered by an aluminium foil to measure dark condition parameters and after 30 minutes of light exposure the photosynthesis parameters for light adapted leaves were measured. Canopy and leaf spectral reflectance were acquired with an SVC HR-1024 (Spectra Vista Corporation) that provides measurements in the $350-2500 \mathrm{~nm}$ spectral range with $1.5 \mathrm{~nm}$ spectral resolutions and $1 \mathrm{~nm}$ sampling step at field and lab. The sensor of the radiometer was placed about $1.00 \mathrm{~m}$ above the canopy at nadir position with a viewing angle of $14^{\circ}$, so that the diameter of the footprint is about $0.246 \mathrm{~m}$ at field. Five observations within each plot data were collected in order to cover the entire plot and characterize its variability.The average value was taken as the measurement for each of the plot. Measurements were taken between 10:00 and 14:30 hours local time (GMT +5.5 hour) under clear sky conditions at field. For each plot, radiance from a white reference panel (BaSO4) was acquired to derive reflectance. Based on reflectance data, various indices are calculated (table1)

\begin{tabular}{|c|c|}
\hline Index Name & Formula \\
\hline Simple Ratio & $S R=R_{N I R} / R$ \\
\hline $\begin{array}{ll}\text { Normalized } & \text { Difference } \\
\text { Vegetation Index } & \end{array}$ & $N D V I=\left(R_{N I R}-R\right) /\left(R_{N I R}+R\right)$ \\
\hline Enhance Vegetation Index & $\begin{array}{l}E V I=2.5 \times \\
\left(R_{N I R}-R\right) /\left(R_{N I R}+6 \times R-7.5 \times R+1\right)\end{array}$ \\
\hline $\begin{array}{l}\text { Visible Atmospherically } \\
\text { Resistant Index }\end{array}$ & $V A R I=(R-R) /(R+R)$ \\
\hline $\begin{array}{l}\text { Normalized Difference Water } \\
\text { Index } 1\end{array}$ & $\begin{array}{l}N D W I 1= \\
\left(R_{V N I R}-R_{N I R}\right) /\left(R_{V N I R}+R_{N I R}\right)\end{array}$ \\
\hline $\begin{array}{l}\text { Normalized Difference Water } \\
\text { Index } 2\end{array}$ & $\begin{array}{l}N D W I 2= \\
\left(R_{V N I R}-R_{\text {SWIRI } 1}\right) /\left(R_{\text {VNIR }}+R_{\text {SWIRI }}\right)\end{array}$ \\
\hline $\begin{array}{l}\text { Normalized Difference Water } \\
\text { Index } 3\end{array}$ & $\begin{array}{l}N D W 13= \\
\left(R_{\text {VNIR }}-R_{\text {SWIR } 2}\right) /\left(R_{\text {VNIR }}+R_{\text {SWIR } 2}\right)\end{array}$ \\
\hline $\begin{array}{l}\text { Hyperspectral Vegetation } \\
\text { Index }\end{array}$ & $H V I=\left(R_{743} / R_{692}\right)$ \\
\hline $\begin{array}{l}\text { Hypersepctral Normalized } \\
\text { Difference Vegetation Index }\end{array}$ & $\begin{array}{l}H N D V I= \\
\left(R_{814}-R_{672}\right) /\left(R_{814}+R_{672}\right)\end{array}$ \\
\hline Greenness Index & $G I=R_{539} / R_{682}$ \\
\hline $\begin{array}{l}\text { Hyperspectral Normalized } \\
\text { Difference Water Index }\end{array}$ & $\begin{array}{l}H N D W I= \\
\left(R_{845}-R_{1256}\right) /\left(R_{845}+R_{1256}\right)\end{array}$ \\
\hline $\begin{array}{l}\text { Normalized } \\
\text { Infrared Index }\end{array}$ & $\begin{array}{l}N D I I= \\
\left(R_{845}-R_{1649}\right) /\left(R_{845}+R_{1649}\right)\end{array}$ \\
\hline Water Index & $W I=R_{895} / R_{983}$ \\
\hline
\end{tabular}




\begin{tabular}{|c|c|}
\hline $\begin{array}{l}\text { Photochemical Reflectance } \\
\text { Index }\end{array}$ & $P R I=\left(R_{529}-R_{580}\right) /\left(R_{529}+R_{580}\right)$ \\
\hline $\begin{array}{l}\text { Red-Edge Vegetation Stress } \\
\text { Index }\end{array}$ & $R V S I=0.5 \times\left(R_{722}+R_{763}\right)-R_{733}$ \\
\hline $\begin{array}{l}\text { Modified Chlorophyll } \\
\text { Absorption Ratio Index }\end{array}$ & $\begin{array}{l}M C A R I=R_{712} \times \\
{\left[\left(R_{712}-R_{682}\right)-0.2 \times\left(R_{712}-R_{539}\right)\right] / R_{682}}\end{array}$ \\
\hline $\begin{array}{l}\text { Transformed Chlorophyll } \\
\text { Absorption Ratio Index }\end{array}$ & $T C A R I=3 \times\left[\begin{array}{l}\left(R_{700}-R_{670}\right)-0.2 \times \\
\left(R_{700}-R_{550}\right) \times\left(\frac{R_{700}}{R_{670}}\right)\end{array}\right]$ \\
\hline Triangular Vegetation Index & $\begin{array}{l}T V I=0.5 \times \\
{\left[120 \times\left(R_{750}-R_{550}\right)-200 \times\left(R_{670}-R_{550}\right)\right]}\end{array}$ \\
\hline Zarco-Tejada\& Miler & $Z M=R_{750} / R_{710}$ \\
\hline Simple R Pigment Index & $S R P I=R_{430} / R_{680}$ \\
\hline $\begin{array}{l}\text { Normalized } \\
\text { Phaeophytinization Index }\end{array}$ & $N Q P I=\left(R_{415}-R_{435}\right) /\left(R_{415}+R_{435}\right)$ \\
\hline $\begin{array}{l}\text { Photochemical } \\
\text { ReflectanceIndex } 1\end{array}$ & $P R I 1=\left(R_{528}-R_{567}\right) /\left(R_{528}+R_{567}\right)$ \\
\hline $\begin{array}{l}\text { Photochemical } \\
\text { ReflectanceIndex } 2\end{array}$ & PRI2 $=\left(R_{531}-R_{570}\right) /\left(R_{531}+R_{570}\right)$ \\
\hline $\begin{array}{l}\text { Normalized } \\
\text { PigmentChlorophyll Index }\end{array}$ & $N P C I=\left(R_{680}-R_{430}\right) /\left(R_{680}+R_{430}\right)$ \\
\hline Carter Indices 1 & $C I 1=R_{695} / R_{420}$ \\
\hline Carter Indices 2 & $C I 2=R_{695} / R_{760}$ \\
\hline Lichtenthaler indices 1 & $L i c 1=\left(R_{800}-R_{680}\right) /\left(R_{800}+R_{680}\right)$ \\
\hline Lichtenthaler indices 2 & $\operatorname{Lic} 2=R_{440} / R_{690}$ \\
\hline $\begin{array}{ll}\text { Structure } & \text { Intensive } \\
\text { PigmentIndex } & \end{array}$ & $S I P I=\left(R_{800}-R_{450}\right) /\left(R_{800}+R_{650}\right)$ \\
\hline Vogelmann indices 1 & $\operatorname{Vog} 1=R_{740} / R_{720}$ \\
\hline Vogelmann indices 2 & $\operatorname{Vog} 2=\left(R_{734}-R_{747}\right) /\left(R_{715}+R_{726}\right)$ \\
\hline Vogelmann indices 3 & $\operatorname{Vog} 3=\left(R_{734}-R_{747}\right) /\left(R_{715}+R_{720}\right)$ \\
\hline Gitelson and Merzlyak 1 & $G M 1=R_{750} / R_{550}$ \\
\hline Gitelson and Merzlyak 2 & $G M 2=R_{750} / R_{700}$ \\
\hline
\end{tabular}

Table-1 List of narrow band indices

\section{RESULT AND DISCUSSIONS}

The main aim of the study is to retrieve the bio-physical parameters using hyperspectral data. The correlations of the biophysical and physiological parameters with narrow band indices are established. The spectral indices are nondestructive relative scale to detect the crop health in shorter time instead of measuring all parameters by various instruments. To carry out the same following steps were followed-

a) Bio-physical parameters (i.e. LAI, CCI) analysis under different treatments

b) Physiological parameters (i.e. $\mathrm{Fv} / \mathrm{Fm}, \mathrm{Fv}^{\prime} / \mathrm{Fm}^{\prime}$ ) analysis under different treatment c) Calculation of hyperspectral indices and correlation analysis to retrieve of bio-physical and physiological parameters at canopy level.

\subsection{Bio-physical parameters}

Leaf area index (LAI) is plotted with respect to various treatments (Figure-1). LAI is representative of the vegetative growth and condition of the crops. The higher value of LAI refers to better crop vegetative condition and vice-versa. Leaf area index (LAI) is plotted with respect to the main plot (irrigation condition) and subplot (boron treatment). In case of main plot treatments, it was observed that the LAI values were increasing as the number of irrigations reduced from six (M1) to five (M2). Whereas, with further decrease in number of irrigation, i.e. at four irrigations (M3), the LAI was found to be decreasing.

In case of subplot treatments, it was interesting to find that under M1, i.e. plots with six irrigations, the highest LAI was observed in case of $0.15 \%$ foliar application of boron. However, with increase in boron application $(0.2 \%)$ it was found to be decreasing. Intermediate LAI values were recorded in case of plots with no boron application under M1 treatment. In case of M2, i.e. plots with five irrigations, the highest LAI was recorded in case of crops with maximum $(0.2 \%)$ boron application, whereas it was almost similar for other two boron treatments, i.e. no and $0.15 \%$ boron applications. In case of M3, i.e. plots with four irrigations, the LAI values were found to be increasing with increasing in boron applications (figure$1)$.

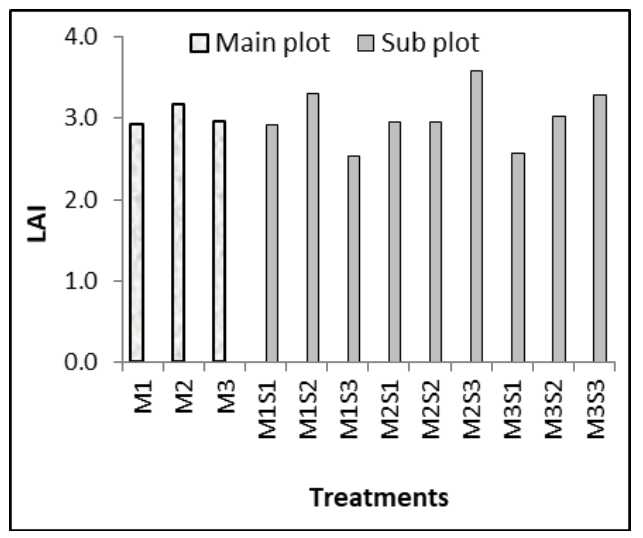

Figure-1 LAI vs Treatments

Chlorophyll Content Index (CCI) indicates the chlorophyll content of crop.The higher values of CCI refer more chlorophyll content of crop and vice-versa. The CCI is quantified as ratio between transmittance at $931 \mathrm{~nm}$ and $653 \mathrm{~nm}$ and provides a relative measurement of chlorophyll concentration. Chlorophyll Content Index (CCI) is plotted with respect to the main plot (irrigation condition) and subplot (boron treatment). Under main plot i.e. irrigation treatments, it was observed that the CCI values were increasing as the number of irrigation reduced from six (M1) to five (M2). With further decrease in number of irrigation, i.e. at four irrigations (M3), the CCI was found to be decreasing.

In case of subplot treatments, it was found that under M1, M3 i.e. plots with six and four irrigations, respectively, the highest CCI was observed in case of $0.15 \%$ foliar application of boron. 
However, with increase in boron application $(0.2 \%)$ it was found to be decreasing. In case of M2, i.e. plots with five irrigations, the CCI values were found to be increasing with increasing in boron applications (Figure-2).

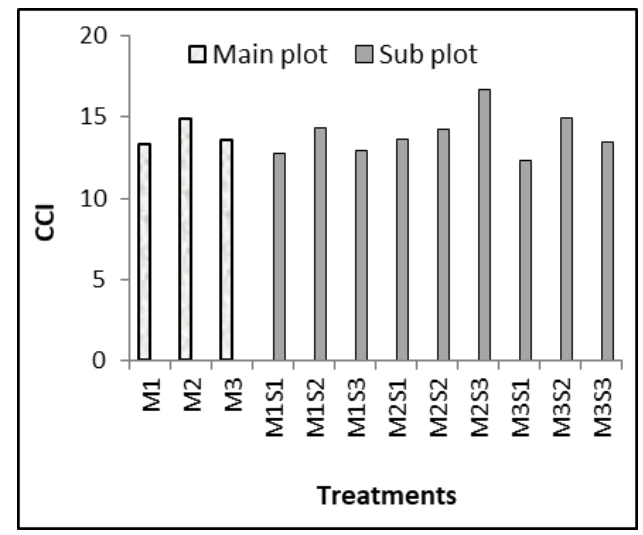

Figure-2 CCI vs Treatments

\subsection{Physiological parameters}

$\mathrm{Fv} / \mathrm{Fm}$ is an estimate of the maximum quantum efficiency of PSII reaction centres. This ratio is calculated from two parameters i.e. Fo and Fm. Fo is the fluorescence level of a dark-adapted plant with all PSII primary acceptors 'open' (QA fully oxidized). Fm is the maximal fluorescence level achieved upon application of a saturating flash of light, such that all primary acceptors 'close' (QA fully reduced). Variable fluorescence, Fv, is the difference between Fo and Fm. The variable to maximal fluorescence ratio is normally between 0.75 and 0.85 , depending on leaf health, age, and preconditioning. It was observed from Figure- 3 that $\mathrm{Fv} / \mathrm{Fm}$ is with normal range of 0.75 to 0.85 for all three types of irrigation. Relatively, M2 was showing better cop health compare to M1 and M3. In sub plot treatments, it was found that no boron and $0.15 \%$ boron application were having almost similar Fv/Fm values, whereas for $0.20 \%$ boron application lower values were recorded. It was interesting to observe that all three levels of boron applications were having almost similar $\mathrm{Fv} / \mathrm{Fm}$ values under M2 irrigation treatment. In case of M3, with increased applications of boron the values of $\mathrm{Fv} / \mathrm{Fm}$ were found to be increasing, representing lesser stress with higher boron applications.

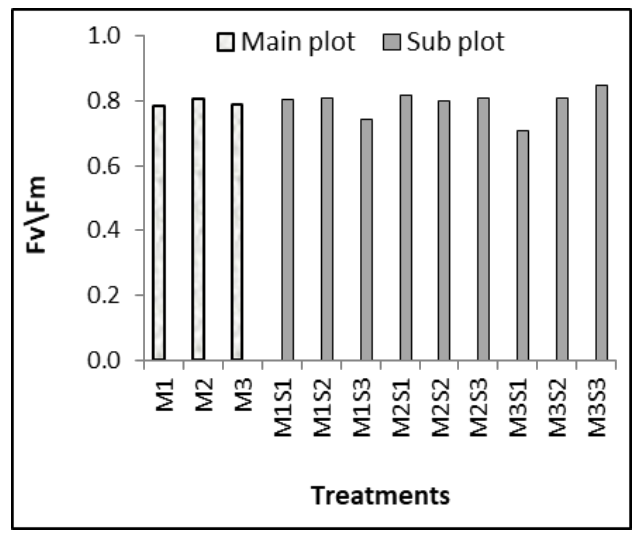

Figure-3 Fv/Fm vs Treatment
$\mathrm{Fv}^{\prime} / \mathrm{Fm}^{\prime}$ is the fraction of absorbed PSII photons that are used in photochemistry, and is measured with a light adapted leaf. It is calculated from Fs and Fm', where Fs is steady-state fluorescence and Fm' is the maximum fluorescence from a light adapted sample upon application of a saturating flash. High light adapted plants tend to have low $\mathrm{Fv}^{\prime} / \mathrm{Fm}^{\prime}$ values because a higher proportion of the absorbed energy is dissipated through non-photochemical processes. Three other useful fluorescence parameters will be explored in this experiment. $\mathrm{Fv}^{\prime} / \mathrm{Fm}^{\prime}$ represents the efficiency of energy harvesting by oxidized (open) PSII reaction centres in the leaf. Two competing processes that quench (decrease) the level of chlorophyll fluorescence in the leaf are referred to as photochemical (qP) and non-photochemical (qN) quenching. All three of these parameters require Fo', the minimal fluorescence (in the dark) of a light-adapted leaf. It was observed from figure- 10 that $\mathrm{Fv}^{\prime} / \mathrm{Fm}^{\prime}$ is below 0.68 for all three types irrigation. M2 was showing higher value of $\mathrm{Fv}^{\prime} / \mathrm{Fm}^{\prime}$ compare to M1 and M3. In sub plot treatments, it was found that no boron and $0.15 \%$ boron application were having almost similar $\mathrm{Fv}^{\prime} / \mathrm{Fm}^{\prime}$ values, whereas for $0.20 \%$ boron application lower values were recorded. It was interesting to observe that all three level of boron applications were having increasing trends $\mathrm{Fv}^{\prime} / \mathrm{Fm}^{\prime}$ values under M2 irrigation treatment. In case of M3 irrigation, with increased applications of boron the values of $\mathrm{Fv}^{\prime} / \mathrm{Fm}$ ' were found to be higher than no boron to $0.15 \%$ foliar application of boron. However, with increase in boron application $(0.2 \%)$ it was found to be decreasing (Figure-4).

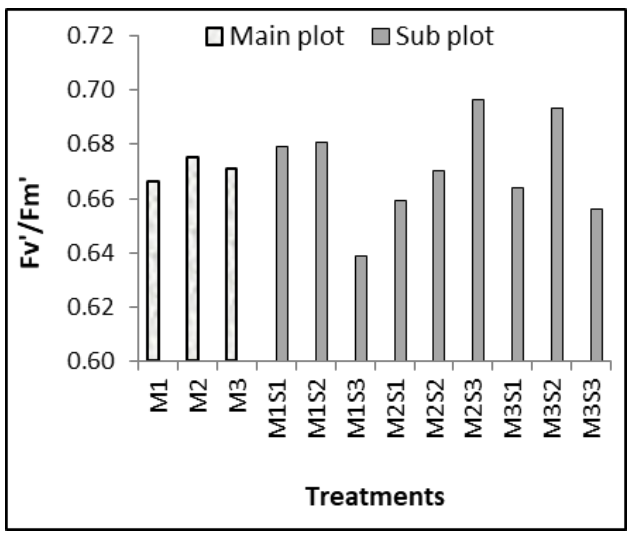

Figure-4 Fv'/Fm' vs Treatment

\subsection{Retrieval Bio-physical and Physiological parameters}

A linear regression was established between the LAI and CCI with individual spectral indices. Similarly, another set linear regression was performed between $\mathrm{Fv} / \mathrm{Fm}$ and $\mathrm{Fv}^{\prime} / \mathrm{Fm}^{\prime}$ with individual spectral indices. Further, multiple regression with all the narrow band indices were carried out to retrieve LAI, CCI, $\mathrm{Fv} / \mathrm{Fm}, \mathrm{Fv}^{\prime} / \mathrm{Fm}^{\prime}$ at canopy level.

Out of these indices it was found some of the indices are having better correlation with LAI and CCI given in table- 2 . The $90 \%$ of significant correlations are given in $(* *)$ and $80 \%$ are given in $(*)$.

\begin{tabular}{|l|l|l|}
\hline \multirow{4}{*}{ Indices } & \multicolumn{2}{|c|}{ Canopy } \\
\cline { 2 - 3 } & LAI & CCI \\
\cline { 2 - 3 } & r-value & r-value \\
\hline
\end{tabular}




\begin{tabular}{|l|l|l|}
\cline { 2 - 3 } CI1 & 0.09 & $-0.74^{* *}$ \\
\hline CI2 & $0.30^{*}$ & $-0.69^{* *}$ \\
\hline GI & 0.01 & $0.30^{*}$ \\
\hline GM1 & $0.40^{* *}$ & $0.60^{* *}$ \\
\hline GM2 & $-0.38^{*}$ & $0.62^{* *}$ \\
\hline PRI & 0.09 & 0.29 \\
\hline PRI1 & -0.13 & $0.77^{* *}$ \\
\hline PRI2 & -0.21 & $0.77^{* *}$ \\
\hline RVSI & $0.39^{* *}$ & 0.25 \\
\hline SIPI & $-0.42^{* *}$ & $0.61^{* *}$ \\
\hline SRPI & -0.10 & $0.78^{* *}$ \\
\hline TVI & -0.02 & $0.53^{* *}$ \\
\hline VARI & 0.03 & $0.26^{*}$ \\
\hline VI1 & $-0.33^{*}$ & $0.61^{* *}$ \\
\hline VI2 & $0.31^{*}$ & $-0.57^{* *}$ \\
\hline VI3 & $0.31^{*}$ & $-0.57^{* *}$ \\
\hline WI & 0.08 & 0.02 \\
\hline ZM & $-0.34^{*}$ & $0.63^{* *}$ \\
\hline
\end{tabular}

Table-2 Correlation coefficient between narrow band indices and bio physical parameters

For LAI retrieval Structure Intensive Pigment Index (SIPI), Red-Edge Vegetation Stress index (RVSI), Gitelson and Merzlyak1 (GM1), Gitelson and Merzlyak2 (GM2) and ZarcoTejada \& Miler (ZM) showed higher correlation than other indices.

Gitelson and Merzlyak1 (GM1) is plotted with Leaf Area Index (LAI) with regression value $\mathrm{r}=0.40$ as shown in Figure5 .

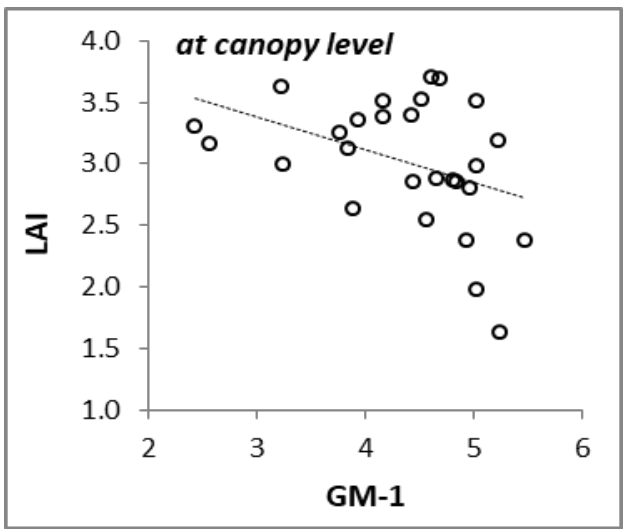

Figure-5 LAI vs GM-1

For CCI retrieval Carter Indices 1 (CI1), Carter Indices 2 (CI2), Photochemical ReflectanceIndex 1 (PRI), Photochemical ReflectanceIndex 2 (PRI2) and Simple R Pigment Index (SRPI) showed higher correlation than other indices.

Simple Ratio Pigment Index (SRPI) is plotted with Chlorophyll Content Index (CCI) with regression value $\mathrm{r}=0.78$ (Figure-6).

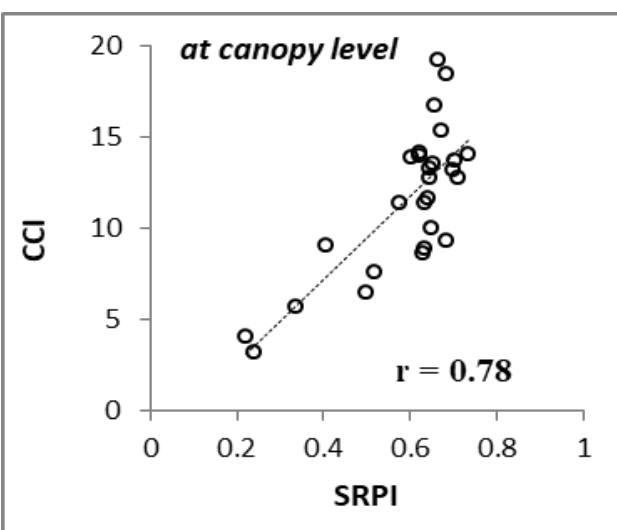

Figure-6 SRPI vs CCI

Out of these indices it was found some of the indices are having better correlation with $\mathrm{Fv} / \mathrm{Fm}$ and $\mathrm{Fv}^{\prime} / \mathrm{Fm}^{\prime}$ given in table-3 for dark and light condition of leaf. About $90 \%$ of significant correlations are given in $\left({ }^{* *}\right)$ notation and $80 \%$ are given in (*).

\begin{tabular}{|l|l|l|}
\hline \multirow{2}{*}{ Indices } & \multicolumn{2}{|c|}{ Canopy } \\
\cline { 2 - 3 } & Fv/Fm & Fv'/Fm' \\
\cline { 2 - 3 } & r-value & r-value \\
\hline VARI & 0.04 & 0.13 \\
\hline GI & 0.01 & 0.22 \\
\hline ZM & -0.25 & $-0.40^{*}$ \\
\hline SRPI & 0.11 & -0.35 \\
\hline NPQI & $-0.41^{* *}$ & 0.13 \\
\hline NPCI & -0.07 & 0.36 \\
\hline CI1 & -0.10 & $0.38^{*}$ \\
\hline CI2 & 0.24 & $0.42^{* *}$ \\
\hline LI1 & -0.26 & $-0.41^{*}$ \\
\hline LI2 & 0.10 & -0.35 \\
\hline SIPI & $-0.38^{*}$ & -0.37 \\
\hline VI1 & -0.25 & $-0.39^{*}$ \\
\hline VI2 & 0.25 & $0.37^{*}$ \\
\hline VI3 & 0.25 & $0.37^{*}$ \\
\hline GM1 & $-0.30^{*}$ & $0.44^{* *}$ \\
\hline GM2 & $-0.27^{*}$ & $-0.39^{*}$ \\
\hline PRI1 & -0.06 & $-0.40^{* *}$ \\
\hline PRI2 & -0.13 & $-0.39^{*}$ \\
\hline RVSI & $0.38^{*}$ & $0.39^{*}$ \\
\hline
\end{tabular}

Table-3 Correlation coefficient between narrow band indices and physiological parameters

Once again to retrieve Fv/Fm, Normalized Phaeophytinization Index (NPQI), Structure Intensive Pigment Index (SIPI), RedEdge Vegetation Stress index (RVSI), Gitelson and Merzlyak1 (GM1), and Gitelson and Merzlyak2 (GM2) showed higher correlation than other indices. 
Normalized Phaeophytinization Index (NPQI) is plotted with $\mathrm{Fv} / \mathrm{Fm}$ for dark condition with regression value $\mathrm{r}=-0.41$ (Figure-7).

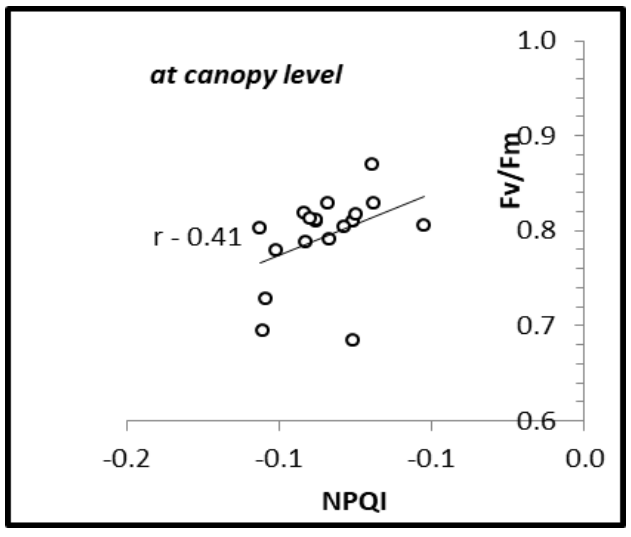

Figure-7 Fv/Fm vs NQPI

Similar way again to retrieve Fv'/Fm', Zarco-Tejada \& Miler (ZM), Lichtenthaler indices 1 (LI 1), Photochemical ReflectanceIndex 1 (PRI1), Gitelson and Merzlyak1 (GM1), and Carter Indices 2 (CI2) showed higher correlation than other indices.

Gitelson and Merzlyak1 (GM1) is plotted with $\mathrm{Fv}^{\prime} / \mathrm{Fm}^{\prime}$ for light condition with regression value $\mathrm{r}=0.44$ (Figure- 8 ).

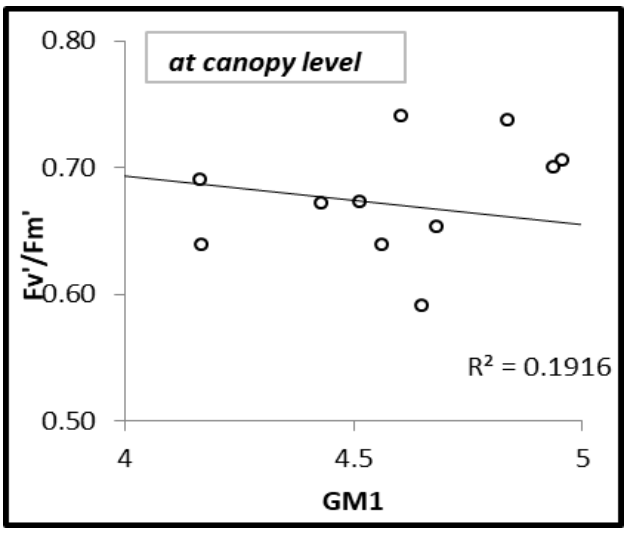

Figure-8 Fv'/Fm' vs GM1

The results obtained from multiple regressions are given in Table-4.

\begin{tabular}{|l|l|l|}
\hline Parameters & Correlation & \multicolumn{1}{|c|}{ Indices } \\
\hline LAI & 0.87 & $\begin{array}{l}\text { RVSI, SIPI, CI-2, GM-1, } \\
\text { ZM, PRI-1 (Refer -9) }\end{array}$ \\
\hline CCI & 0.79 & SRPI, RVSI (Refer-10) \\
\hline Fv/Fm & 0.92 & $\begin{array}{l}\text { RVSI, SRPI, PRI-2, NPQI, } \\
\text { SIPI, VI-3, ZM (Refer -11) }\end{array}$ \\
\hline Fv'/Fm' & 0.76 & $\begin{array}{l}\text { RVSI, GM-1, GM-2, CI-1 } \\
\text { (Refer-12) }\end{array}$ \\
\hline
\end{tabular}

Table-4 Multiple regressions
The biophysical parameters, LAI \& CCI and physiological parameters, $\mathrm{Fv} / \mathrm{Fm} \& \mathrm{Fv}^{\prime} / \mathrm{Fm}^{\prime}$ were retrieved using the identified indices along with the regression parameters (Figure9 to 12) It was found the narrow band indices were able to retrieve both bio-physical and physiological parameters with high accuracy.

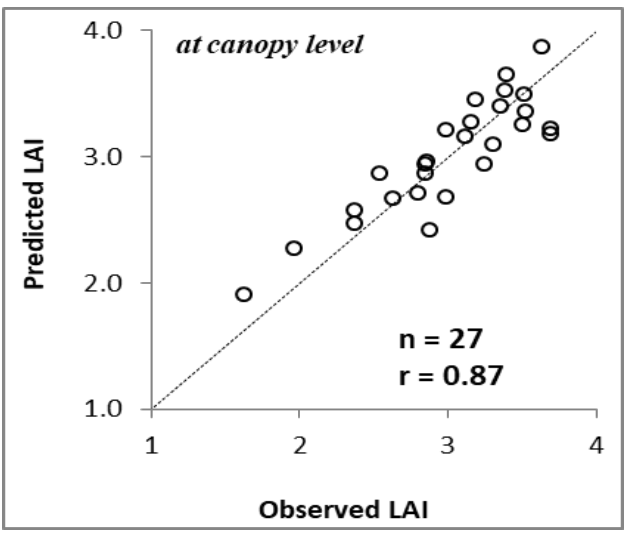

Figure-9 Predicted LAI vs Observed LAI

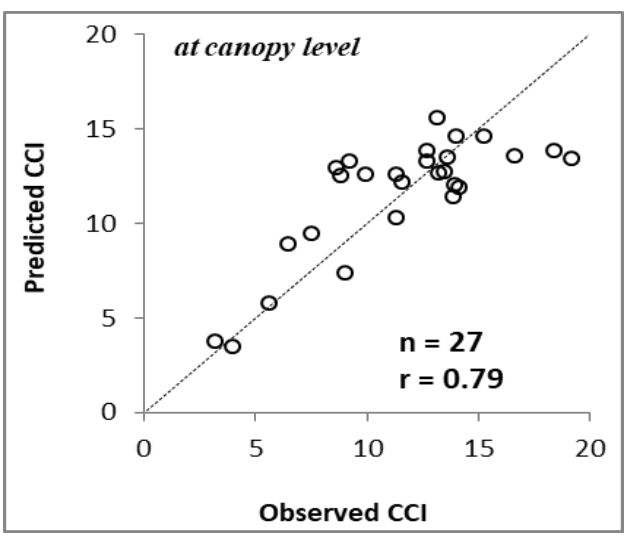

Figure-10 Predicted CCI vs Observed CCI

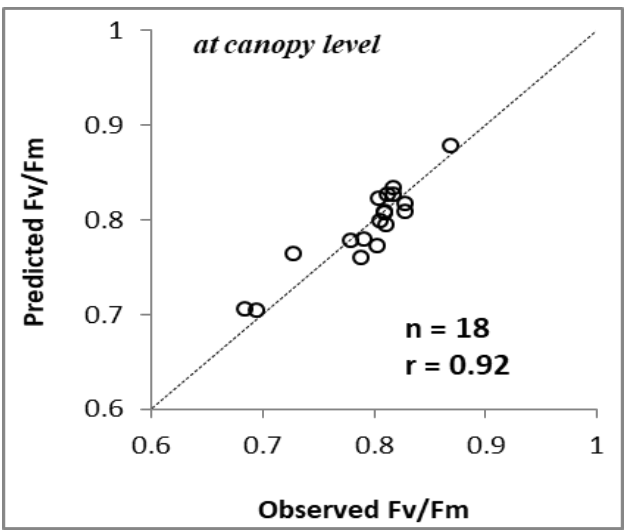

Figure-11Predicted Fv/Fm vs Observed Fv/Fm 


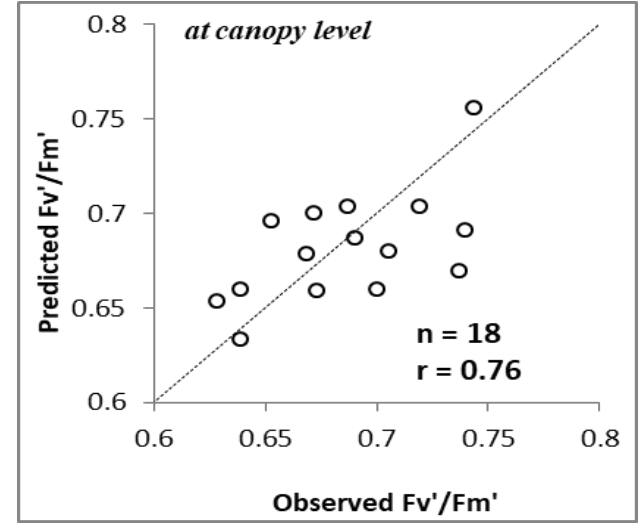

Figure-12 Predicted Fv'/Fm' vs Observed Fv'/Fm'

\section{CONCLUSION}

M2 i.e. medium irrigation is found to be optimum for better crop health which is reflected in terms of bio physical and physiological parameters in both LAI and CCI. Moreover, $\mathrm{M} 2 \mathrm{~S} 3$ is found to be even better combination for growth of sun flower crop. Narrow band indices were derived and linear as well as multiple regressions were carried out. It was found fives indices i.e. Structure Intensive Pigment Index (SIPI), RedEdge Vegetation Stress index (RVSI), Gitelson and Merzlyak1 (GM1), Gitelson and Merzlyak2 (GM2) and Zarco-Tejada \& Miler (ZM) are able to retrieve bio-physical parameter (LAI) with higher accuracy. Whereas, Carter Indices 1 (CI1), Carter Indices 2 (CI2), Photochemical Reflectance Index 1 (PRI1), Photochemical Reflectance Index 2 (PRI2) and Simple R Pigment Index (SRPI) indices are able to retrieve CCI in linear regression with 80 to $90 \%$ accuracy. Similar way, physiological parameters are also retrieved in linear regression fit for both light and dark condition i.e. $\mathrm{Fv}^{\prime} / \mathrm{Fm}^{\prime}$ and $\mathrm{Fv} / \mathrm{Fm}$ respectively. The multiple regressions also followed to retrieve narrow bio-physical and physiological parameter from 76 to $92 \%$ accuracy. Overall, the narrow band indices were able to retrieve both bio-physical and physiological parameters with high accuracy.

\section{ACKNOWLEDGEMENTS (OPTIONAL)}

We express our sincere thanks to Dr Santanu Choudwary, Director, National Remote Sensing Centre.

\section{REFERENCES}

Kanemasu, Niblett, Manges, Lenhert, Newman, 1974, Wheat: Its Growth and Disease Severity as Deduced From ERTS-1, Remote Sensing of the Environment 3: 255-260

Paul Heckbert, 1995, Fourier Transforms and the Fast Fourier Transform (FFT) Algorithm, Revised 27 Jan. 1998 , https://www.cs.cmu.edu/.../2001/pub/www/notes/fourier/fourier. pdf.

Prabir Kumar Das, Karun Kumar Choudhary, B. Laxman, S.V.C. Kameswara Rao \& M.V.R. Seshasai, 2014, A modified linear extrapolation approach towards red edge position detection and stress monitoring of wheat crop using hyperspectral data., International Journal of Remote Sensing, http://www.tandfonline.com/loi/tres20.
Wei Feng , Shuangli Qi , Yarong Heng , Yi Zhou , Yapeng $\mathrm{Wu}$, Wandai Liu , Li He and Xiao Li , 2017. Canopy Vegetation Incies from In situ Hyperspectral Data to Assess Plant Water Status of Winter Wheat under Powdery Mildew Stress,InPlantScience, https://www.frontiersin.org/articles/10.3 389/fpls.2017.01219

Zarco-Tejada, Berjón, Miller, 2004. Stress Detection in Crops with Hyperspectral Remote Sensing and Physical Simulation Models researchgate, http://digital.csic.es/ bitstream/10261/10582/1/40.pdf). 